agriTECH, 41 (1) 2021, 49-57

\title{
Effect of Antioxidant and Pro-oxidant on the Stability of Microencapsulated Squalene by Spray Drying
}

\author{
Dwi Ayuni ${ }^{1}$, Joko Nugroho Wahyu Karyadi ${ }^{1}$, Arifin Dwi Saputro ${ }^{1}$, Hidefumi Yoshii2* \\ ${ }^{1}$ Department of Agricultural and Bio-systems Engineering, Universitas Gadjah Mada, \\ Jl. Flora No. 1, Bulaksumur, Yogyakarta 55281, Indonesia \\ 2Department of Food Science and Nutrition, Setsunan University, \\ 45-1 Nagaotoge-cho, Hirakata, Osaka 573-0101, Japan \\ *Corresponding author: Hidefumi Yoshii, Email: hidefumi.yoshii@setsunan.ac.jp
}

Submission: December 20, 2019; Revision: June 9, 2020; Acceptance: July 27, 2020

\begin{abstract}
Natural hydrocarbon compounds are extremely in high demand across various applications. For instance, squalene (SQ) is widely used in cosmetic and food supplement industries, due to beneficial health components. The aim of this study was to investigate the potentials of antioxidant addition on the physical properties, as well as SQ stability in spray-dried powder at various oil droplet diameters $(0.3-4 \mu \mathrm{m})$. Rosemary oil extract served as antioxidant, while iron (II) sulfate accelerated the oxidation. Subsequently, SQ stability was evaluated at four separate temperatures, termed $25,50,70$, and $105^{\circ} \mathrm{C}$, after one month storage. Also, the morphological structures of the samples were characterized with scanning electron microscopy (SEM). The results showed the oil

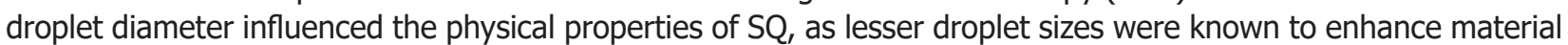
strength. Furthermore, antioxidant inclusion proved to be effective in inhibiting oxidation, particularly in powders with large oil droplet diameter. The high regression coefficients $\left(R^{2}>0.97\right)$ and reduced chi-square confirmed Weibull model acceptance in predicting the retention of SQ content.
\end{abstract}

Keywords: Encapsulation; oil-droplet diameter; spray drying; squalene oil; stability

\section{INTRODUCTION}

Sea foods are very rich in practically all fundamental supplements and micronutrients needed to maintain a balanced health. An essential micronutrient includes the squalene (SQ), a natural hydrocarbon compound known to occur in plants and animals, with diverse physiological capabilities (Hosomi et al., 2012). In animals, SQ exists abundantly in the liver oil of deep-sea shark (60 wt \%), while in plants, considerable amounts are present in olive oil (Naziri et al., 2014). This substance is predominantly applied in cosmetic and functional foods industries, as a result of notable beneficial health components.

However, due to high level of unsaturation, SQ is easily influenced by certain factors, including temperature, moisture content, oxygen, and metals, leading to oxidation and degradative retention. This condition potentially causes rancidity and off-flavor, specifically in food products. Therefore, to solve the problem, microencapsulation technique is commonly employed, where a core material e.g. lipid, is enclosed by a polymeric compound, called the microencapsulating agent, to form an emulsion, followed by drying the resulting sample to generate microcapsules (Paramita et al., 2012). The process tends to control the release rate of core materials, and also support the protection against oxidation (Munin \& Edwards-Lévy, 2011). Several microencapsulation studies using spray drying and the application to functional oils have been conducted, although, very few focused on SQ encapsulation. 
The wall materials, including maltodextrin (MD) with different dextrose equivalent (DE), are important factors influencing the morphology of spray-dried powder. In the formation of the encapsulated powder, the use of emulsifiers become very essential. In addition, casein shows this ability by the interaction with the samples and stabilization of emulsion droplets (Jayasundera et al., 2009). However, Shen et al. (2010) reported the strength of fish oil microencapsulation was significantly improved with blends of chitosan, modified starch, and glucose.

Apart from the wall factor, core material retention primarily depends on droplet size during emulsification. Lesser dimensions contribute to lower surface oil content, and in turn, results to higher retention, oxidation, and stability. Among other homogenization methods, high-pressure successfully produced small oil-droplets (Samani \& Naji, 2019). The process possibly causes protein deterioration and relatively high operating costs, and therefore becomes a major concern this study seeks to address by identifying a novel and relatively inexpensive approach, but of superior quality.

The joint application of antioxidants and wall materials in microencapsulation is perceived as an effective method in preventing oxidation. Rosemary oil extract serves as a natural antioxidant commonly employed to delay lipid oxidation in fish oil/emulsion systems (Yang et al., 2016). Also, Terpinc et al., (2009) previously determined the antioxidant activity in a mixture of linoleic acid and $\beta$-carotene. The reports showed high content of phenolic extract (final concentration of $0.04 \mathrm{mg} / \mathrm{mL}$ ) contributed to reduce $\beta$-carotene bleaching. Meanwhile, iron $\left(\mathrm{Fe}^{2+} / \mathrm{Fe}^{3+}\right)$ was applied as an influential accelerator for the oxidation of fat, despite obtaining lesser concentration. In addition, the metal iron was observed in every production stage, from raw to packing materials, particularly in foods, irrespective of other sources, including tap water and steel processing tools. Furthermore, Wu et al. (2016) involved iron (II) chloride to promote lipid oxidation in krill oil-in-water emulsions. The results showed the iron, as a prominent pro-oxidant, triggered a rapid increase in lipid hydroperoxide, after barely a day storage.

The objective of this study is to investigate the effect of oil droplet diameter on the stability of encapsulated SQ in spray-dried powder, and also to evaluate the potentials of antioxidant in preventing oxidation. Subsequently, pro-oxidant was introduced as a new variable to provide further comprehension on the influence of oxidant variables on the system. In summary, three oil droplet diameters and three oxidant variables were utilized to generate and then analyze
SQ in spray-dried dusts, particularly in the surface oil content, powder morphology, and product stability at various storage temperatures.

\section{MATERIALS AND METHODS}

\section{Materials}

Squalene was purchased from Tokyo Chemical Industry Co., Ltd and maltodextrin (MD) from Matsutani Chemical Industry Co., Ltd, Hyogo. Also, sodium caseinate (NC) and lecithin (LT) were mutually acquired from Miyoshi Oil \& Fat Co., Ltd, while Rosemary oil extract as antioxidant (Anti), was purchased from Mitsubishi-Chemical Foods Corporation, both also in Tokyo. The iron (II) sulfate heptahydrate $\left(\mathrm{Fe}_{2} \mathrm{SO}_{4}\right)$ as pro-oxidant (Pro), and other substances were procured from Wako Pure Chemical Industries, Ltd, Osaka. These companies are all situated in Japan.

\section{Methods}

\section{Preparation of feed emulsions}

A $3 \times 3$ factorial experimental design was employed in the experiments with oil droplets of small diameter (Sd), medium (Md), and large (Ld). Also, the variables included 2 wt\% RM (Anti), and 100 ppm $\mathrm{Fe}_{2} \mathrm{SO}_{4}$ (Pro), but with no oxidant as a reference (Ref). Table 1 represents the sample code names and experimental designs. Furthermore, total solid content is comprised of $40 \mathrm{wt} \% \mathrm{SQ}, 3 \mathrm{wt} \% \mathrm{NC}, 54.6-56.6$ wt $\%$ MD, and 0.4 wt\% LT. However, MD with DE of 19 served as wall material (Ghani et al., 2017), while NC associated with LT were employed as an emulsifier (Hoang Thi et al., 2013).

The MD and NC were dispersed in distilled water, using Bio shaker (BR - 13 UM Taitec, Saitama, Japan) 110 rpm at $50{ }^{\circ} \mathrm{C}$, and was reserved overnight for complete dissolution. Subsequently, oil-in-water emulsions were prepared by adding SQ previously mixed with $\mathrm{LT}$, to separate aqueous phase. Moreover, for antioxidant (Anti) variable, RM was combined with $\mathrm{SQ}$ and $\mathrm{LT}$, while for pro-oxidant (Pro), $\mathrm{Fe}_{2} \mathrm{SO}_{4}$ was added to the distilled water prior to MD and NC.

However, the samples were subjected to Polytron Rotor-stator (PT 6100 Kinematica GA, Littau, Switzerland), operating at $8000 \mathrm{rpm}$ for 3 minutes with 30 -s intervals for every minute at room temperature. The homogenized emulsions were further processed to high-pressure homogenizer (HJP-25001K Sugino, Uozu, Japan) at $100 \mathrm{MPa}$ at $50^{\circ} \mathrm{C}$ for two cycles, in an effort to obtained smaller oil-droplet diameters. 
Table 1. Experimental design applied for microencapsulated SQ production

\begin{tabular}{|c|c|c|c|}
\hline \multirow[b]{2}{*}{$\begin{array}{l}\text { Sample } \\
\text { names }\end{array}$} & \multicolumn{3}{|c|}{ Variables } \\
\hline & $\begin{array}{l}\text { Total solids } \\
\text { (wt\%) }\end{array}$ & $\begin{array}{c}\text { Homogenization } \\
\text { process }\end{array}$ & $\begin{array}{l}\text { Atomizer } \\
\text { speed during } \\
\text { spray drying } \\
\text { (rpm) }\end{array}$ \\
\hline Sd-Ref & 40 & $\begin{array}{l}\text { rotor stator + high } \\
\text { pressure }\end{array}$ & 10,000 \\
\hline Sd-Anti & 40 & $\begin{array}{l}\text { rotor stator + high } \\
\text { pressure }\end{array}$ & 10,000 \\
\hline Sd-Pro & 40 & $\begin{array}{l}\text { rotor stator + high } \\
\text { pressure }\end{array}$ & 10,000 \\
\hline Md-Ref & 60 & rotor stator & 30,000 \\
\hline Md-Anti & 60 & rotor stator & 30,000 \\
\hline Md-Pro & 60 & rotor stator & 30,000 \\
\hline Ld-Ref & 40 & rotor stator & 10,000 \\
\hline Ld-Anti & 40 & rotor stator & 10,000 \\
\hline Ld-Pro & 40 & rotor stator & 10,000 \\
\hline
\end{tabular}

\section{Emulsion Viscosity}

The viscosity of feed emulsions was measured at $50{ }^{\circ} \mathrm{C}$, using R/S plus rheometer (DVII+ Brookfield Engineering Lab, Inc. MA, USA) equipped with rotating cone plate. Individual sample was analyzed in triplicate, with a new substance for separate replicate.

\section{Spray Drying}

This process was performed in a pilot-plant spray dryer (Ohkawara L-8 spary dryer Kakouki Co. Ltd. Yokohama, Japan) armed with rotary atomizer. The inlet and outlet temperatures was set to $140^{\circ} \mathrm{C}$ and $80-90^{\circ} \mathrm{C}$, respectively, while feed flow rate was specified at 25 $\mathrm{mL} / \mathrm{min}$, although, air flow rate was adjusted to 110 $\mathrm{kg} / \mathrm{h}$. Consequently, precipitates from spray drying were stored prior to analysis at $-30^{\circ} \mathrm{C}$ in an aluminum bag under a nitrogen atmosphere.

\section{Oil Droplet Size Distribution}

The oil droplet diameter in both emulsion or spraydried powder, and particle diameter distribution was determined, using laser diffraction particle size analyzer (SALD-7100 Shimadzu Corp., Kyoto, Japan) equipped with a batch sample cell. Diameter distribution refers to the ratio of certain particle size to the total volume of sample. The distance is believed to be uniform for a narrow distribution. However, to determine oil droplet diameter in either emulsion or spray-dried powder, the sample was first dissolved in distilled water prior to inclusion into matrix, with the aim of destroying the wall materials, while for powder particle, 2-Methyl-1propanol was introduced in place of distilled water. Each sample was analyzed in triplicate and the mean values of the volume mean diameter $\left(D_{4,3}\right)$ with confidential intervals of $95 \%$ was reported.

\section{Moisture Content}

The moisture content evaluation of separate samples was performed with halogen moisture analyzer (Mettler Toledo, Ohio, America) at $160^{\circ} \mathrm{C}$. Also, each sample was analyzed in triplicate.

\section{Scanning Electron Microscopy (SEM)}

Scanning electron microscopy (SEM; JSM 6060 JEOL Ltd., Tokyo, Japan) was employed to observe an enlarged image of the morphology and cross-section of encapsulated SQ. Prior to analysis, these samples were obtained by manual fracturing, using mortar and pestle, and were then coated with Pt-Pd, under a magnetron sputter (MSP-1S IXRF Systems Inc, Texas, USA) operating at accelerated current of $30 \mathrm{~mA}$ for 1 -2 minutes. Furthermore, magnification to present the general morphology and cross-sectional image were specified at 200 and 2,500 times, respectively.

\section{Encapsulated Yield}

Encapsulated yield is the ratio of oil successfully captured from the matrix to the total oil in powder. However, to determine this value, total and surface oil of SQ were first evaluated, according to Shiga et al. (2014) with slight modification. To measure surface oil content, $100 \mathrm{mg}$ of SQ powder was dissolved in $4 \mathrm{ml}$ of hexane solution, using Eyela Mixture (CM-1000 Tokyo Rikakikai Co. LTD.) at 1,600 rpm for 15 minutes. Also, to ascertain total oil content, similar sample quantity was first dissolved in $4 \mathrm{ml}$ of dimethylformamide (DMF) prior to extraction, in order to destroy the wall materials. Subsequently, centrifugation was conducted, using Tabletop Centrifuge 2410 (Kubota Corp., Tokyo, Japan) operated at 3,000 rpm for 10 minutes.

Chromatographic separation in hexane phase was performed with GC-FID (GC-2010 Shimadzu Corp., Kyoto, Japan) equipped with ULBON HR-1 (Ø0.25 mm x $30 \mathrm{~m} \times 0.5 \mu \mathrm{m}$ ) column and operated as follows: SPL (Injector) Temp., $280^{\circ} \mathrm{C}$; Column Temp., $270{ }^{\circ} \mathrm{C}$; FID (Detector) Temp., $300{ }^{\circ} \mathrm{C}$; carrier gas, nitrogen; and retention time: 13 minutes.

\section{Stability of the SQ Oil Powder}

The SQ powders were reserved for one month at $25,50,70$, and $105^{\circ} \mathrm{C}$ in a drying oven (SA 460 Masuda Corp., Osaka, Japan). Also, SQ was then sampled 
and extracted at predetermined time to measure the remaining amount of total oil.

Retention $(R)=\frac{\text { (remaining amout of } \mathrm{SQ} \text { ) }}{\text { (initial amount of } \mathrm{SQ} \text { in the powder) }}$

The SQ retention is expected to gradually decrease during storage, as shown by the retention graph. In addition, Weibull distribution function was then employed to describe the degradation. This model is widely applied in food engineering, due to the simplicity and flexibility in estimating the parameters (Corzo et al., 2010). The Weibull distribution function for this research is determined in Eq. (2)

$R=\exp \left[-(k t)^{n}\right]$

where $R[-]$ is the SQ retention, $t$ (day) is the storage time, $k\left(\right.$ day $\left.^{-1}\right)$ is the degradation rate constant, and $n$ is the parameter for degradation mechanism.

\section{Statistical analysis}

The SQ properties were subjected to variance analysis (ANOVA) with $95 \%$ significance level, using IBM SPSS Statistics 23 software (SPSS Inc., Chicago, IL). As the requirements for homogeneity of variances were satisfied, Tukey test was performed to examine sample variation.

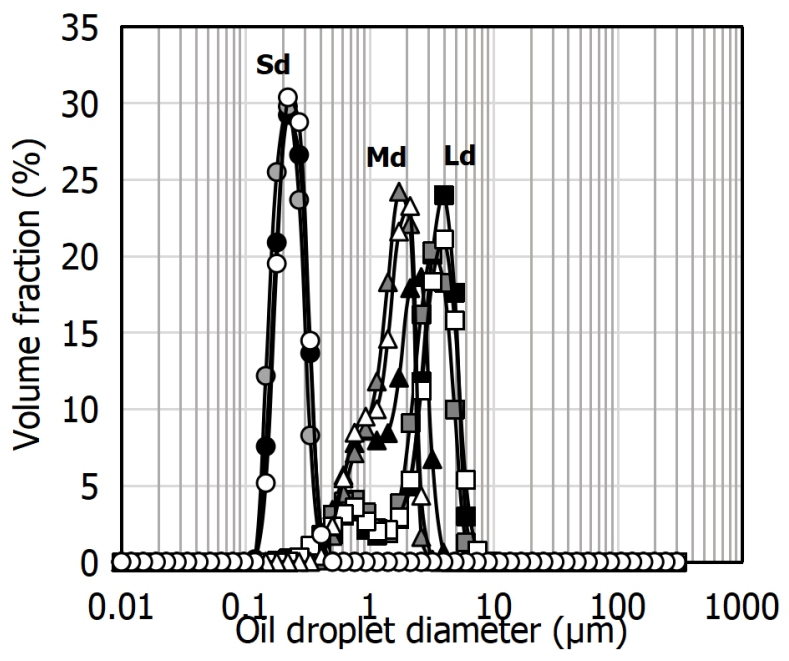

(a)

\section{RESULTS AND DISCUSSIONS}

\section{Oil Droplet Size Distribution aand Moisture Content}

Figure 1 and Table 2 represent SQ oil characteristics in emulsions and spray-dried powders, respectively. Separate experimental designs produced mixtures characterized by varying mean oil droplet size, in both media. The solutions prepared with high-pressure (Sd) were monomodal and also obtained the narrowest distribution $(p<0.05)$ and were distinguished by the smallest $D_{4,3 \prime}$ around $0.2 \mu \mathrm{m}(n=3)$. Meanwhile, with only rotor-stator homogenizer (Md and Ld), the blends were shown to be bimodal and all acquired wider $D_{4,3^{\prime}}$ compared to Sd ( $p<0.05)$, almost 10 times bigger. This result was similar to previous research by Shiga et al. (2017), although, with significantly unstable mean diameters $D_{4,3}$. The graph illustrated the distribution of Md and Ld to overlap each other, but after spray drying, the variation became more pronounced.

The powders prepared by rotor-stator homogenizer, and with sufficient concentration (Md), were observed to be monodal with $D_{4,3}$ around $1 \mu \mathrm{m}(n=3)$. These samples apparently obtained smaller oil-droplet diameter and narrower distribution, compared to $\mathrm{Ld}(\mathrm{p}<0.05)$. The results confirmed previous researches, where abundant solid content triggered greater viscosity, and then relatively homogeneous droplet sizes. Higher emulsion viscosity tends to restrict the oil droplets, therefore, leading to the inability to form bigger droplet sizes, particularly in spray drying (Carmona et al., 2013; Jafari et al., 2008). The addition of both antioxidant

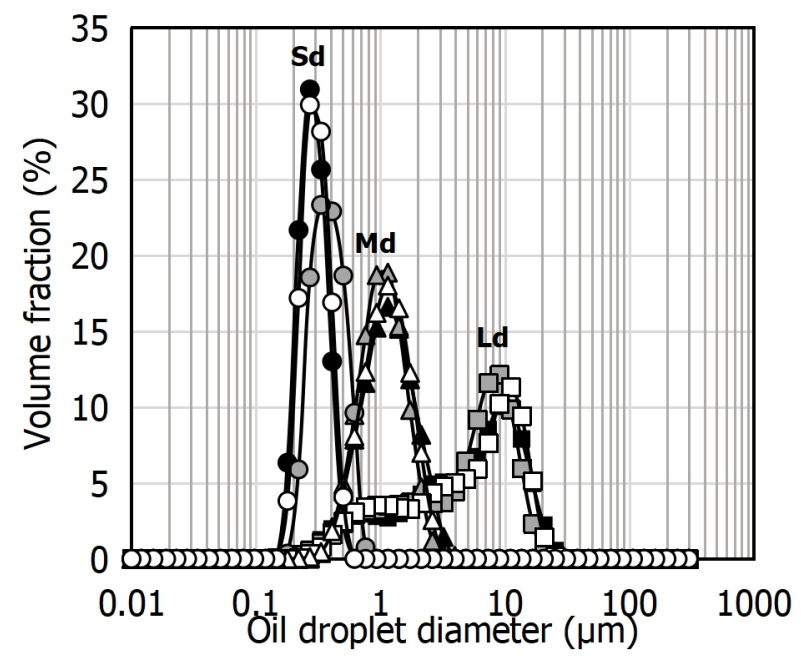

(b)

Figure 1. Oil-droplet size distributions of SQ in emulsions (a) in spray-dried powders (b).

Black symbol represent reference, gray symbol represent antioxidant, and white symbol pro-oxidant, With Sd: $, \bigcirc, \bigcirc$; Md: $\mathbf{\Delta}, \triangle, \triangle$; Ld: $\boldsymbol{\square}, \square, \square$ 
Table 2. Characteristics of emulsions and spray-dried powders of SQ oil

\begin{tabular}{lccccc}
\hline \multirow{2}{*}{ Samples } & \multicolumn{2}{c}{ Emulsions } & \multicolumn{3}{c}{ Spray-dried powders } \\
\cline { 2 - 6 } & $\begin{array}{c}\text { Volume mean } \\
\text { diameter } \\
\left(D_{4,3}\right),(\mu \mathrm{m})\end{array}$ & $\begin{array}{c}\text { Viscosity } \\
(\mathrm{mPa} . \mathrm{s})\end{array}$ & $\begin{array}{c}\text { Volume mean } \\
\text { diameter }\left(D_{4,3}\right), \\
(\mu \mathrm{m})\end{array}$ & $\begin{array}{c}\text { Powder } \\
\text { diameters } \\
\left(D v_{0.9}\right),(\mu \mathrm{m})\end{array}$ & $\begin{array}{c}\text { Moisture Content } \\
(\%)\end{array}$ \\
\hline Sd - Ref & $0.21 \pm 0.11^{\mathrm{b}}$ & $3.96 \pm 0.28^{\mathrm{b}}$ & $0.26 \pm 0.00^{\mathrm{a}}$ & $50.56 \pm 0.12^{\mathrm{e}}$ & $2.12 \pm 0.22^{\mathrm{a}}$ \\
Sd - Anti & $0.20 \pm 0.11^{\mathrm{a}}$ & $6.44 \pm 0.46^{\mathrm{c}}$ & $0.34 \pm 0.01^{\mathrm{c}}$ & $54.66 \pm 0.10^{\mathrm{g}}$ & $2.35 \pm 0.15^{\mathrm{abc}}$ \\
Sd - Pro & $0.21 \pm 0.11^{\mathrm{b}}$ & $2.83 \pm 0.15^{\mathrm{a}}$ & $0.27 \pm 0.11^{\mathrm{b}}$ & $53.80 \pm 0.20^{\mathrm{f}}$ & $2.73 \pm 0.21^{\mathrm{cd}}$ \\
Md-Ref & $1.35 \pm 0.25^{\mathrm{d}}$ & $68.77 \pm 4.14^{\mathrm{de}}$ & $1.03 \pm 0.21^{\mathrm{e}}$ & $37.45 \pm 0.19^{\mathrm{b}}$ & $2.55 \pm 0.15^{\mathrm{bcd}}$ \\
Md - Anti & $1.26 \pm 0.17^{\mathrm{c}}$ & $64.19 \pm 2.43^{\mathrm{d}}$ & $0.92 \pm 0.18^{\mathrm{d}}$ & $38.45 \pm 0.18^{\mathrm{c}}$ & $2.78 \pm 0.09^{\mathrm{de}}$ \\
Md - Pro & $1.25 \pm 0.19^{\mathrm{c}}$ & $81.94 \pm 5.15^{\mathrm{e}}$ & $1.00 \pm 0.19^{\mathrm{e}}$ & $34.86 \pm 0.20^{\mathrm{a}}$ & $2.80 \pm 0.03^{\mathrm{de}}$ \\
Ld - Ref & $2.47 \pm 0.29^{\mathrm{f}}$ & $2.92 \pm 0.27^{\mathrm{a}}$ & $3.74 \pm 0.07^{\mathrm{a}}$ & $44.84 \pm 0.10^{\mathrm{d}}$ & $2.32 \pm 0.15^{\mathrm{ab}}$ \\
Ld - Anti & $2.11 \pm 0.30^{\mathrm{e}}$ & $2.91 \pm 0.29^{\mathrm{a}}$ & $3.53 \pm 0.07^{\mathrm{f}}$ & $61.13 \pm 0.18^{\mathrm{h}}$ & $2.18 \pm 0.01^{\mathrm{ab}}$ \\
Ld - Pro & $2.37 \pm 0.31^{\mathrm{f}}$ & $2.97 \pm 0.42^{\mathrm{a}}$ & $3.69 \pm 0.08^{\mathrm{fg}}$ & $51.42 \pm 0.34^{\mathrm{h}}$ & $3.17 \pm 0.09^{\mathrm{e}}$ \\
\hline
\end{tabular}

Data represent mean \pm standard deviation $(n=3)$

Different letters in the same row indicate significant differences $(p<0.05)$ among samples.

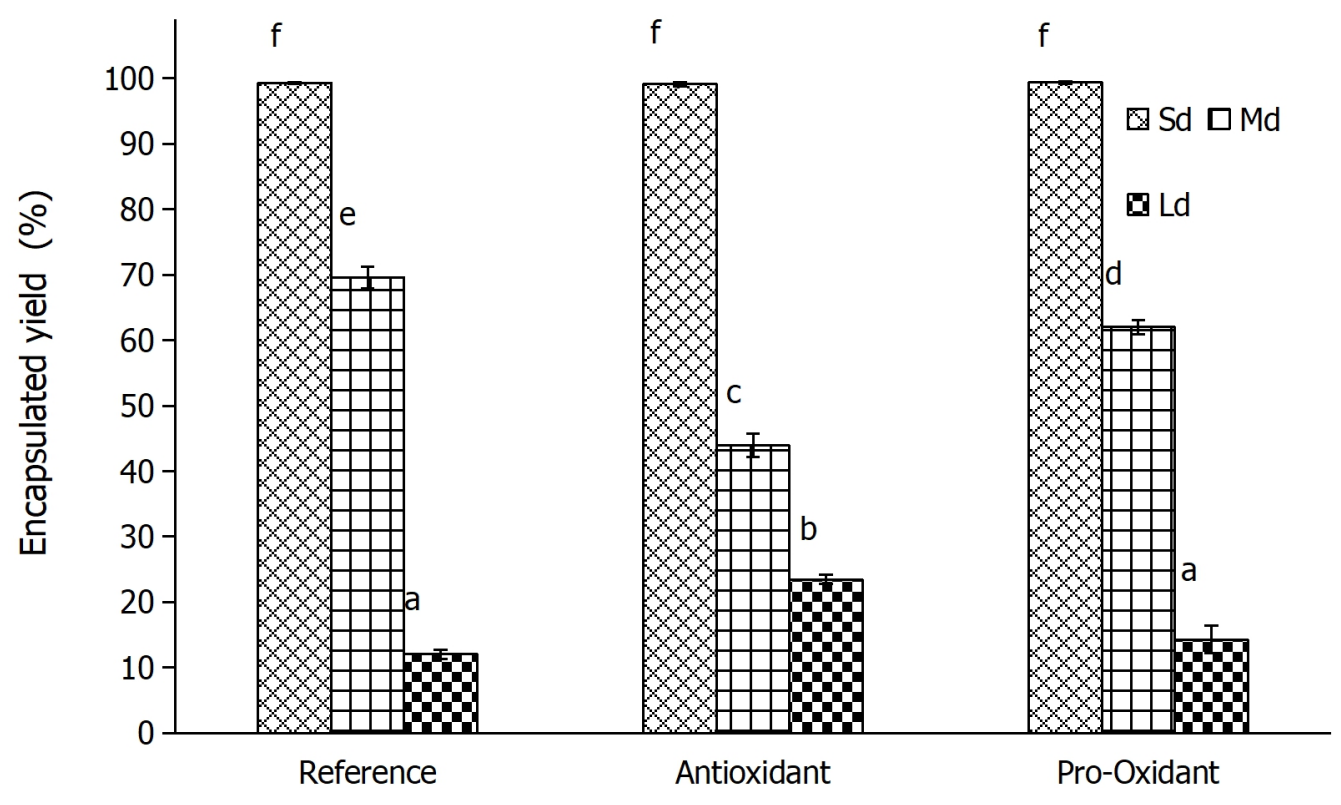

Different letters per parameter indicate significant differences $(p<0.05)$ among samples.

Figure 2. Encapsulated yield of SQ in spray-dried powders

and pro-oxidant were proven to generate constraints to the distribution of oil droplet diameter, in emulsions and spray-dried powders. These conditions matched the report by Liu et al. (2015), where only slight variations were detected on mean particle diameters. Furthermore, Wu et al. (2016) indicated the use of iron to promote oxidation on krill oil, produced minimal effect on physical stability of emulsions.
In the case of moisture content in spray-dried powders, the entire samples occur between the range of $2-3 \%$ and the dimensional variables were not able to influence the powder diameters. However, the addition of antioxidant showed slightly greater oil droplet width, probably due to similar introduction believed to instigate a decline in the ratio of sodium caseinate to carbohydrate, as well as in the accessibility to stabilize 


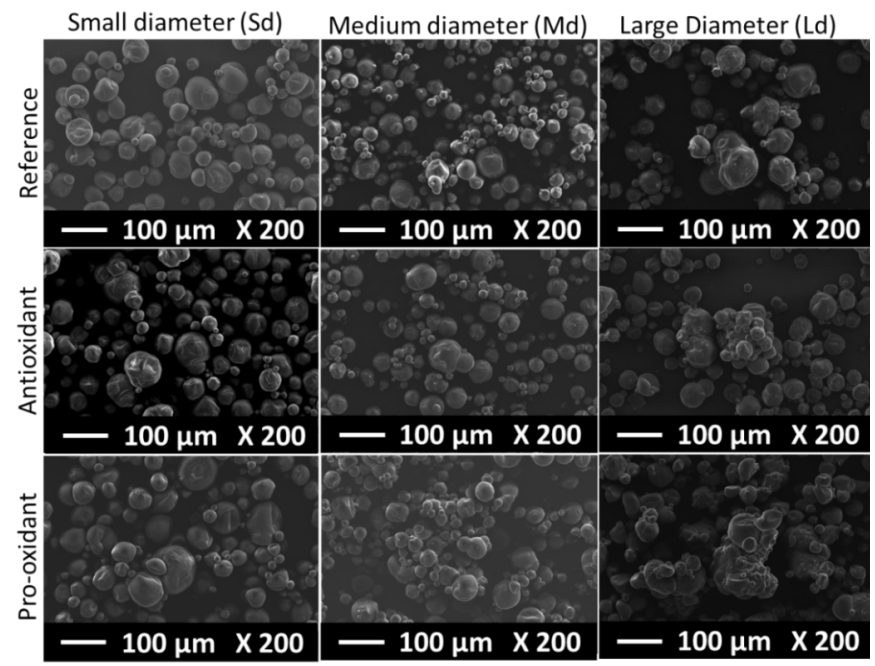

(A)

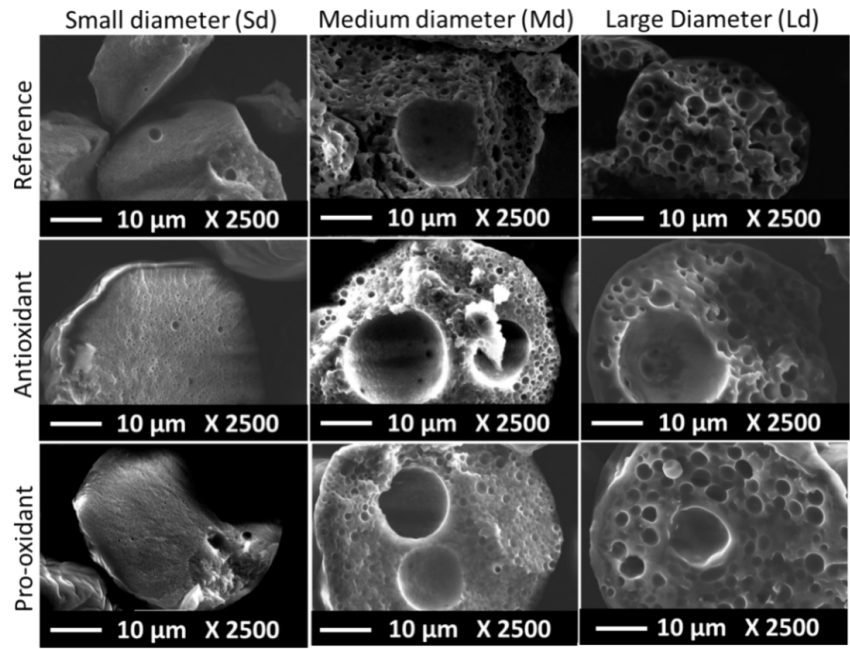

(B)

Figure 3. SEM Images of powder surface structures at 200 times (a) and 2,500 times magnification (b)

air/water interface during atomization (Hogan et al., 2001).

\section{Encapsulated Yield}

Previous study reported a lower encapsulated SQ to total oil ratio, denoting a higher surface oil (Frascareli et al., 2012), but with more air exposure, vulnerability to evaporation, and loss of core materials. Figure 2 showed the encapsulated yield in spray-dried powders, where larger oil droplet diameter tends to lower this ratio $(p<0.05)$. The results supported the provision by Jafari et al. (2008), where emulsions with larger droplet size were more susceptible to droplet breakdown during atomization, and this generates a more extensive surface oil in the microcapsules produced.

\section{Morphology of Visualization of Spray-dried Powder by SEM}

Figure 3 shows the SEM images of SQ surface and cross-section in spray-dried powders. In general, the entire dusts possess similar rounded surfaces, as described by separate authors (Gallardo et al., 2013; Pourashouri et al., 2014). Powders with substantial oil droplet diameters (Ld) was assumed to agglomerate and adhere to each other, or form a larger mass, compared to the rest samples. The agglomeration was probably due to surface oil existence, known to trigger the formation of permanent link (Frascareli et al., 2012). This further confirmed the previous results discussed above, as the absolute cross-sectional images showed vacuoles inside the sample, as evident in multiple-core capsules, where during the drying state, core materials were expanded and distributed throughout the wall. Meanwhile, the center portion appeared vacant or void (Jafari et al., 2008). However, extensive oil droplet size indicates a narrower distance between oil and powder surface, therefore, the oil is possibly oxidized.

\section{Stability of Encapsulated SQ Powders}

Figure 4 shows SQ stability in spray-dried powders as a plot of SQ retention against incubation time. The upper row values indicated the incubation data at 25 and $50{ }^{\circ} \mathrm{C}$, while for the bottom row, 70 and $105^{\circ} \mathrm{C}$ were obtained. In addition, the graph of retention/degradation revealed an exponential tendency in the drying curves, and was validated, using Weibul distribution model. High determination coefficients and low $x^{2}$ values $(p>0.05$, not shown) suggests the model was suitable to predict the degradation of SQ retention in spray-dried powder, and from the parameters, e.g degradation rate constant and shape, the effect of oil droplet and oxidant variables are potentially comprehended (Eq. 2; data not shown). However, shape factor appears to be related to initial speed of mass transfer. Therefore, lesser parameter resulted to more degradation at the commencement of storage (Miranda et al., 2010).

In high temperatures, larger oil-droplet diameter tend to generate higher degradation rate constant $(p<$ $0.05)$. Conversely, small diameter (Sd) showed relatively lowest degradation rates, compared to other sizes. As suggested by Ghani et al. (2016), this phenomenon was attributed to the oxidation reaction, due to the 
propagative transfer rate of radical oxidation between oil droplets. Also, the mechanism of the oxidation and SQ degradation is, however, under investigation.

Based on the shape parameter results, addition of pro-oxidant is capable of accelerating oxidation in small diameter variables (Sd-Pro), but not for bigger oil-droplets without the inclusion (Ld-Ref and Md-Ref) ( $p>0.05$ ). These findings indicated extensive oil droplet appear more vulnerable to oxidation, particularly in extreme conditions, as supported by previous study on oxidative stability of encapsulated flaxseed oil (Shiga et al., 2017) and $d$-limonene (Soottitantawat et al., 2003). However, the antioxidant did not show any significant difference in degradation rate constant, compared to other samples, even in powder with large diameter (Ld-Anti and MdAnti). This confirmed the role of antioxidant in preventing oxidation (Jin et al., 2019; Yeşilsu \& Özyurt, 2019), and to also support powder with larger oil droplet diameter, in order to effectively perform similarly to small oil droplet. Furthermore, Weibull distribution has been applied as a common kinetic model to correlate degradation mechanism in solid-state reactions. This model was reported to successfully match the drying curve in the case of flavor release from spray-dried powder (Sultana \& Yoshii, 2019).
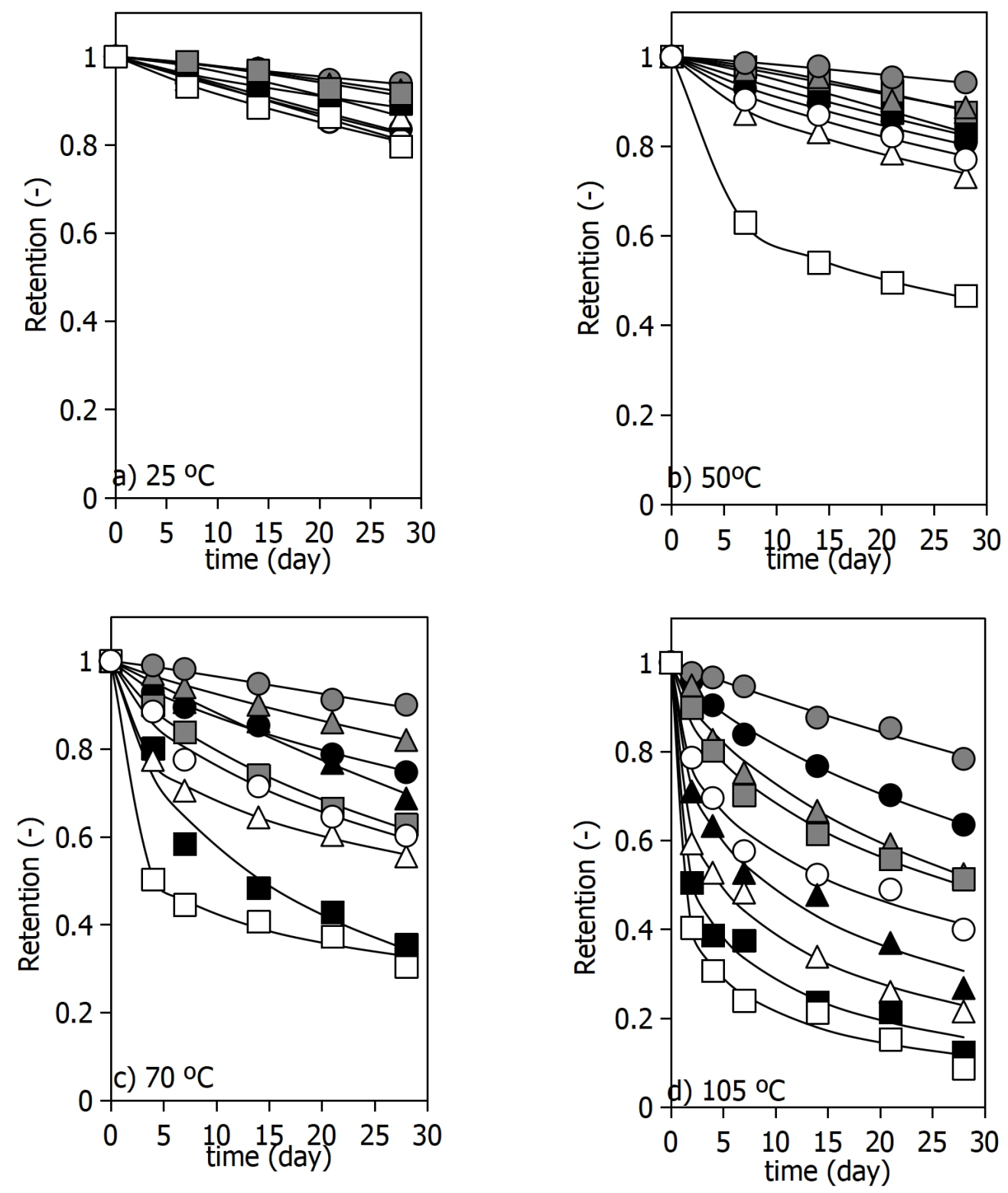

Figure 4. Retention of SQ in spray-dried powders (Weibull distribution model). Black symbol represent reference, gray symbol represent antioxidant, and white symbol pro-oxidant, With Sd: $\bullet, \bigcirc, \bigcirc$; Md: $\mathbf{\Lambda}, \triangle, \triangle$; Ld: $\mathbf{\square}, \square, \square$ 


\section{CONCLUSION}

Based on results and discussion, this experiment has confirmed the influence of oil droplet diameter on the physical properties of squalene (SQ) in spraydried powders. These characteristics include oil droplet size distribution in emulsion and spray-dried powder, encapsulated yield, and powder morphology. Lesser droplet dimensions tend to reduce surface oil content, and instigate higher particle stability. Consequently, the addition of antioxidant and pro-oxidant did not observe any significant variation in the properties, but showed substantial effect on oxidative stability. Furthermore, minimal oil droplet size was proven to be relatively resistance to oxidation, initiated by involving prooxidant. Similarly, antioxidant was confirmed to be very effective in refraining oxidation occurrence, specifically in powder with large oil droplet diameter. Therefore, the optimum percentage of antioxidant added to SQ demands further discussions.

\section{ACKNOWLEDGEMENT}

This study was conducted as part of the joint research grant from Japan Student Services Organization (JASSO).

\section{CONFLICT OF INTEREST}

There is no conflict of interest regarding the publication of this article.

\section{REFERENCES}

Amiri Samani, S., \& Naji, M. H. (2019). Effect of homogenizer pressure and temperature on physicochemical, oxidative stability, viscosity, droplet size, and sensory properties of Sesame vegetable cream. Food Science and Nutrition, 7(3), 899-906. https://doi.org/10.1002/fsn3.680

Carmona, P. A. O., Tonon, R. V., da Cunha, R. L., \& Hubinger, M. D. (2013). Influence of Emulsion Properties on the Microencapsulation of Orange Essential Oil by Spray Drying. Journal of Colloid Science and Biotechnology, 2(2), 130-139. https://doi.org/10.1166/jcsb.2013.1042

Corzo, O., Bracho, N., \& Alvarez, C. (2010). Weibull model for thin-layer drying of mango slices at different maturity stages. Journal of Food Processing and Preservation, 34(6), 993-1008. https://doi.org/10.1111/j.17454549.2009.00433.x

Frascareli, E. C., Silva, V. M., Tonon, R. V., \& Hubinger, M. D. (2012). Effect of process conditions on the microencapsulation of coffee oil by spray drying. Food and Bioproducts Processing, 90(3), 413-424. https:// doi.org/10.1016/j.fbp.2011.12.002

Gallardo, G., Guida, L., Martinez, V., López, M. C., Bernhardt, D., Blasco, R., Pedroza-Islas, R., \& Hermida, L. G. (2013). Microencapsulation of linseed oil by spray drying for functional food application. Food Research International, 52(2), 473-482. https://doi.org/10.1016/j. foodres.2013.01.020

Ghani, A. A., Adachi, S., Shiga, H., Neoh, T. L., Adachi, S., \& Yoshii, H. (2017). Effect of different dextrose equivalents of maltodextrin on oxidation stability in encapsulated fish oil by spray drying. Bioscience, Biotechnology and Biochemistry, 81(4), 705-711. https://doi.org/10.1080/ 09168451.2017 .1281721

Ghani, A. A., Matsumura, K., Yamauchi, A., Shiga, H., Adachi, S., \& Izumi, H. (2016). Effects of oil-droplet diameter on the stability of squalene oil in spray-dried powder. Drying Technology, 34(14).

Hoang Thi, T. H., Lemdani, M., \& Flament, M. P. (2013). Use of calcium caseinate in association with lecithin for masking the bitterness of acetaminophen - Comparative study with sodium caseinate. International Journal of Pharmaceutics, 456(2), 382-389. https://doi. org/10.1016/j.ijpharm.2013.08.075

Hogan, S. A., McNamee, B. F., O'Riordan, E. D., \& O'Sullivan, M. (2001). Emulsification and microencapsulation properties of sodium caseinate/carbohydrate blends. International Dairy Journal, 11(3), 137-144. https://doi. org/10.1016/S0958-6946(01)00091-7

Hosomi, R., Yoshida, M., \& Fukunaga, K. (2012). Seafood consumption and components for health. Global Journal of Health Science, 4(3), 72-86. https://doi.org/10.5539/ gjhs.v4n3p72

Jafari, S. M., Assadpoor, E., He, Y., \& Bhandari, B. (2008). Encapsulation efficiency of food flavours and oils during spray drying. Drying Technology, 26(7), 816-835. https://doi.org/10.1080/07373930802135972

Jayasundera, M., Adhikari, B., Aldred, P., \& Ghandi, A. (2009). Surface modification of spray dried food and emulsion powders with surface-active proteins: A review. Journal of Food Engineering, 93(3), 266-277. https://doi. org/10.1016/j.jfoodeng.2009.01.036

Jin, Y., Liu, Z., Liu, D., Shi, G., Liu, D., Yang, Y., Gu, H., Yang, L., \& Zhou, Z. (2019). Natural antioxidant of rosemary extract used as an additive in the ultrasound-assisted extraction of anthocyanins from lingonberry (Vaccinium vitis-idaea L.) pomace. Industrial Crops and Products, 138(March), 111425. https://doi.org/10.1016/j.indcrop.2019.05.074

Liu, Y., Hou, Z., Yang, J., \& Gao, Y. (2015). Effects of antioxidants on the stability of $\beta$-Carotene in $\mathrm{O} / \mathrm{W}$ 
emulsions stabilized by Gum Arabic. Journal of Food Science and Technology, 52(6), 3300-3311. https://doi. org/10.1007/s13197-014-1380-0

Miranda, M., Vega-Gálvez, A., García, P., Di Scala, K., Shi, J., Xue, S., \& Uribe, E. (2010). Effect of temperature on structural properties of Aloe vera (Aloe barbadensis Miller) gel and Weibull distribution for modelling drying process. Food and Bioproducts Processing, 88(2-3), 138-144. https://doi.org/10.1016/j.fbp.2009.06.001

Munin, A., \& Edwards-Lévy, F. (2011). Encapsulation of natural polyphenolic compounds; a review. In Pharmaceutics (Vol. 3, Issue 4). https://doi.org/10.3390/ pharmaceutics3040793

Naziri, E., Consonni, R., \& Tsimidou, M. Z. (2014). Squalene oxidation products: Monitoring the formation, characterisation and pro-oxidant activity. European Journal of Lipid Science and Technology, 116(10), 14001411. https://doi.org/10.1002/ejlt.201300506

Paramita, V., Furuta, T., \& Yoshii, H. (2012). High-Oil-Load Encapsulation of Medium-Chain Triglycerides and d-Limonene Mixture in Modified Starch by Spray Drying. Journal of Food Science, 77(2), 38-44. https://doi. org/10.1111/j.1750-3841.2011.02534.x

Pourashouri, P., Shabanpour, B., Razavi, S. H., Jafari, S. M., Shabani, A., \& Aubourg, S. P. (2014). Impact of Wall Materials on Physicochemical Properties of Microencapsulated Fish Oil by Spray Drying. Food and Bioprocess Technology, 7(8), 2354-2365. https://doi. org/10.1007/s11947-013-1241-2

Shen, Z., Augustin, M. A., Sanguansri, L., \& Cheng, L. J. (2010). Oxidative stability of microencapsulated fish oil powders stabilized by blends of chitosan, modified starch, and glucose. Journal of Agricultural and Food Chemistry, 58(7), 4487-4493. https://doi.org/10.1021/jf904102k

Shiga, H., Adachi, S., Adachi, S., \& Yoshii, H. (2014). A simple method for determining the flaxseed or fish oil content with $\mathrm{N}, \mathrm{N}$-dimethylformamide in microcapsules prepared by spray drying. Japan Journal of Food Engineering, 15(3), 131-139. https://doi.org/10.11301/jsfe.15.131
Shiga, H., Neoh, T. L., Ninomiya, A., Adachi, S., Pasten, I. L., Adachi, S., \& Yoshii, H. (2017). Effect of oil droplet size on the oxidative stability of spray-dried flaxseed oil powders. Bioscience, Biotechnology and Biochemistry, 81(4), 698-704. https://doi.org/10.1080/09168451.20 17.1281720

Soottitantawat, A., Yoshii, H., Furuta, T., Ohkawara, M., \& Linko, P. (2003). Microencapsulation by spray drying: Influence of emulsion size on the retention of volatile compounds. Journal of Food Science, 68(7), 2256-2262. https://doi.org/10.1111/j.1365-2621.2003.tb05756.x

Sultana, A., \& Yoshii, H. (2019). Kinetic study of controlled release of flavor compounds from spray-dried encapsulated yeast powder using dynamic vapor sorption-gas chromatography. Bioscience, Biotechnology and Biochemistry, 83(4), 738-746. https://doi.org/10.1 080/09168451.2018.1564618

Terpinc, P., Bezjak, M., \& Abramovič, H. (2009). A kinetic model for evaluation of the antioxidant activity of several rosemary extracts. Food Chemistry, 115(2), 740-744. https://doi.org/10.1016/j.foodchem.2008.12.033

Wu, Q., Uluata, S., Cui, L., Wang, C., Li, D., McClements, J., \& Decker, E. A. (2016). Physical and oxidation stability of self-emulsifying krill oil-in-water emulsions. Food and Function, 7(8), 3590-3598. https://doi.org/10.1039/ c6fo00045b

Yang, Y., Song, X., Sui, X., Qi, B., Wang, Z., Li, Y., \& Jiang, L. (2016). Rosemary extract can be used as a synthetic antioxidant to improve vegetable oil oxidative stability. Industrial Crops and Products, 80, 141-147. https://doi. org/10.1016/j.indcrop.2015.11.044

Yeşilsu, A. F., \& Özyurt, G. (2019). Oxidative stability of microencapsulated fish oil with rosemary, thyme and laurel extracts: A kinetic assessment. Journal of Food Engineering, 240(14), 171-182. https://doi. org/10.1016/j.jfoodeng.2018.07.021 